\title{
A survey of the anti-apoptotic Bcl-2 subfamily expression in cancer types provides a platform to predict the efficacy of Bcl-2 antagonists in cancer therapy
}

\author{
WJ Placzek ${ }^{1}$, J Wei ${ }^{1}$, S Kitada ${ }^{1}$, D Zhai ${ }^{1}$, JC Reed ${ }^{1}$ and M Pellecchia*,1
}

We investigated the mRNA expression levels of all six antiapoptotic Bcl-2 subfamily members in 68 human cancer cell lines using qPCR techniques and measured the ability of known Bcl-2 inhibitors to induce cell death in 36 of the studied tumor cell lines. Our study reveals that Mcl-1 represents the anti-apoptotic Bcl-2 subfamily member with the highest mRNA levels in the lung, prostate, breast, ovarian, renal, and glioma cancer cell lines. In leukemia/lymphoma and melanoma cancer cell lines, $\mathrm{Bcl}-2$ and $\mathrm{Bfl}-1$ had the highest levels of mRNA, respectively. The observed correlation between the cell killing properties of known Bcl-2 inhibitors and the relative mRNA expression levels of anti-apoptotic $\mathrm{Bcl}-2$ proteins provide critical insights into apoptosis-based anticancer strategies that target Bcl-2 proteins. Our data may explain current challenges of selective Bcl-2 inhibitors in the clinic, given that severe expression of Bcl-2 seems to be limited to leukemia cell lines. Furthermore, our data suggest that in most cancer types a strategy targeted to Mcl-1 inhibition, or combination of Bfl-1 and Mcl-1 inhibition for melanoma, may prove to be more successful than therapies targeting only $\mathrm{Bcl}-2$.

Cell Death and Disease (2010) 1, e40; doi:10.1038/cddis.2010.18; published online 6 May 2010

Subject Category: Neuroscience

This is an open-access article distributed under the terms of the Creative Commons Attribution License, which permits distribution and reproduction in any medium, provided the original author and source are credited. This license does not permit commercial exploitation without specific permission.

Programmed cell death (apoptosis) represents a physiological process for removing damaged or infected cells and maintaining tissue homeostasis. ${ }^{1}$ During tumorigenesis, cancer cells develop the ability to avoid apoptosis through the upregulation of anti-apoptotic proteins and/or downregulation of proapoptotic signaling pathways. Such measures allow cancer cells to survive even when challenged with chemotherapeutic or DNA-damaging compounds that would normally trigger cytotoxic responses. The Bcl-2 (B-cell lymphoma/leukemia-2) family of both pro- and antiapoptotic proteins are central regulators of apoptosis. This family of at least 26 proteins is divided into three groups, or subfamilies, on the basis of their function and the composition of their $\mathrm{Bcl}-2$ homology $(\mathrm{BH})$ domains. $^{2}$

In humans, six antiapoptotic members of the Bcl-2 family have been identified (Bcl-2, Bcl- $x_{\mathrm{L}}, \mathrm{Bcl}-\mathrm{B}, \mathrm{Bcl}-\mathrm{W}, \mathrm{Bfl}-1$, and $\mathrm{Mcl}-1)$. These proteins contain a hydrophobic cleft that is able to bind to BH3-only proteins and to the pro-apoptotic Bcl-2 family members Bad, Bak, and Bax to inhibit apoptosis. ${ }^{3}$ In the absence of this binding, the proapoptotic Bcl-2 members are recruited to the outer mitochondrial membrane (OMM) at which they oligomerize and cause OMM permeabilization, releasing proapoptotic effectors such as SMAC or cytochrome $c$. The released cytochrome $c$ binds to APAF-1 and pro-caspase 9 to from the apoptosome, which generates mature caspase 9 and begins a proteolytic cascade, ultimately resulting in cell death as shown in Figure $1 .{ }^{4}$ Meanwhile, SMAC release antagonizes a class of caspase inhibitory proteins called IAPs (inhibitor of apoptosis proteins), initiating the apoptotic cascade (Figure 1). Pharmacological inhibition of antiapoptotic Bcl-2 subfamily members and IAP proteins in cancer have emerged as major strategies for allowing intrinsic stress responses to induce apoptosis and cause tumor regression. ${ }^{5}$

Determination of the structure of Bcl-2 and subsequent identification of the $\mathrm{BH}$-binding cleft has allowed the creation of small molecule inhibitors targeting the antiapoptotic Bcl-2 subfamily. ${ }^{6}$ Thus far, nearly all therapeutic compounds

\footnotetext{
${ }^{1}$ Sanford/Burnham Medical Research Institute, 10901 North Torrey Pines Road, La Jolla, CA 92037, USA

${ }^{*}$ Corresponding author: M Pellecchia, Sanford/Burnham Medical Research Institute, North Torrey Pines Road, La Jolla, CA 10901, USA. Tel: + 858 646 3159 ;

Fax: + 858795 5225; E-mail: mpellecchia@burnham.org

Keywords: Bcl-2; Mcl-1; expression; Bfl-1; cancer therapeutics

Abbreviations: APAF-1, apoptotic protease activating factor-1; ATP, adenosine triphosphate; Bcl-2, B-cell lymphoma-2; Bcl-xL, B-cell lymphoma extra-large; $\mathrm{Bcl}-\mathrm{B}, \mathrm{Bcl}-2$ homolog B; Bcl-W, Bcl-2 homolog W; Bfl-1, Bcl-2 related protein A1; BH, Bcl-2 homology domain; cDNA, complementary deoxyribonucleic acid; CNS, central nervous system; DMSO, dimethyl sulfoxide; HDF, human dermal fibroblast; IAPs, inhibitor of apoptosis proteins; IHC, immunohistochemical; LD50, median lethal dose; Mcl-1, myeloid cell leukemia 1 protein; $\mathrm{mRNA}$, messenger ribonucleic acid; OMM, outer mitochondrial membrane; qPCR, quantitative real-time polymerase chain reaction; siRNA, small interfering ribonucleic acid; SMAC, supramolecular activation cluster

Received 10.12.09; revised 24.2.10; accepted 26.3.10; Edited by P Salomoni
} 

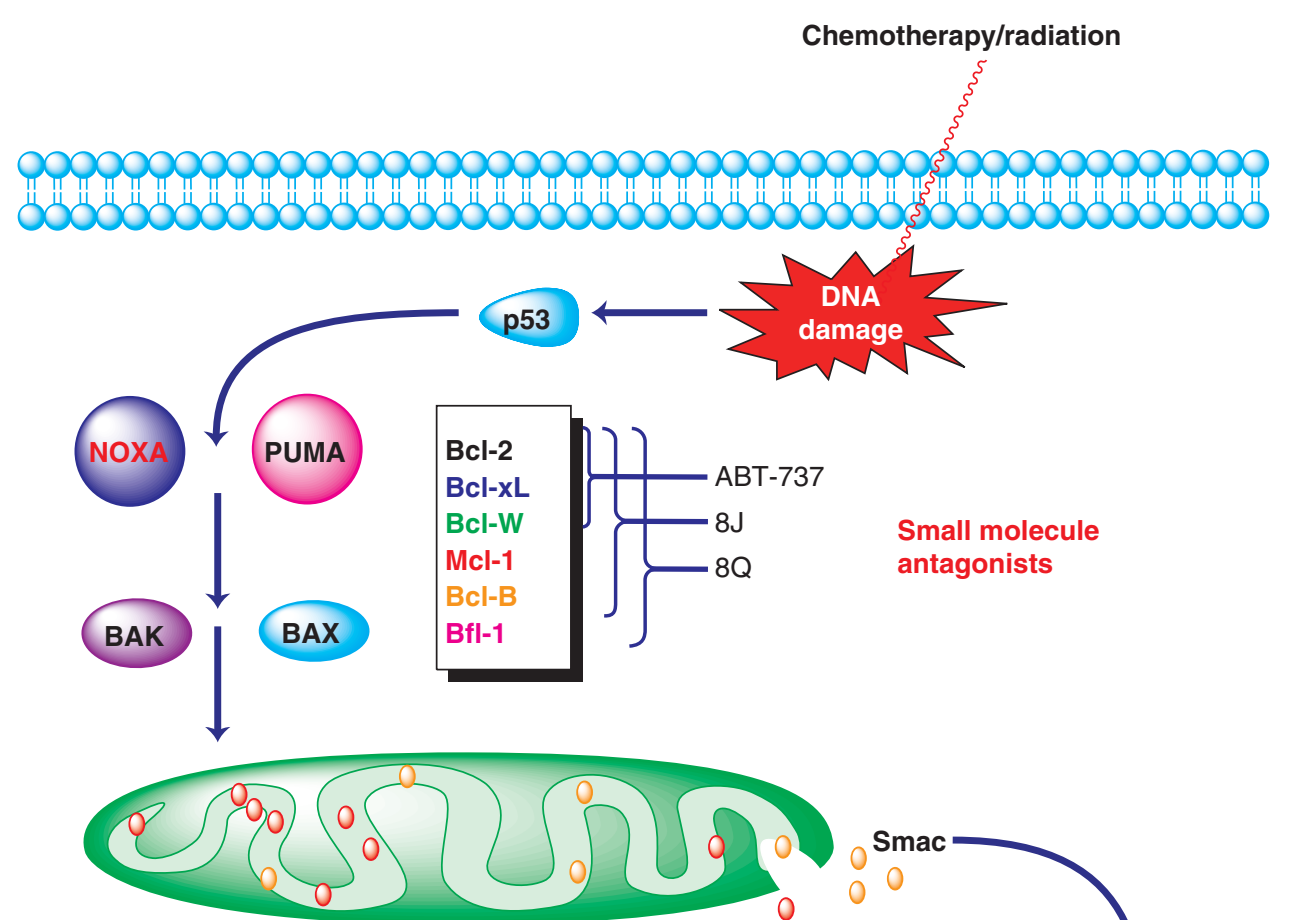

Small molecule antagonists mitochondria

Figure 1 Mechanism of $\mathrm{Bcl}-2$ antagonists in cell stress response. The overexpression of antiapoptotic Bcl-2 proteins induce cancer cell resistance to stress-induced apoptosis. Selective inhibition of a subset of the antiapoptotic Bcl-2 subfamily, as is achieved with ABT-737, has provided promising clinical outcomes, but has also been shown to be overcome through upregulation of Mcl-1 or Bfl-1. Pan-active inhibition of all members of the antiapoptotic Bcl-2 subfamily, as is achieved by the Apogossypol derivative, $8 Q$, prevents suppression of $p 53$-mediated apoptosis and precludes compound resistance through upregulation of other subfamily members

targeting the Bcl-2 family have focused on the inhibition of $\mathrm{Bcl}-2$ and $\mathrm{Bcl}-\mathrm{x}_{\mathrm{L}}$, guided by a large number of immunohistochemical (IHC) studies that have shown these proteins to be upregulated in a variety of tumor types. ${ }^{7-9}$ In breast cancer, these studies observed correlations of Bcl-2 and Mcl-1 with differing clinical end points while making no definitive connections between prognosis and $\mathrm{BCl}-\mathrm{x}_{\mathrm{L}}$ protein levels. ${ }^{7,10}$ Prior studies of CNS tumor samples used IHC and found a significant upregulation of $\mathrm{Bcl}-2$ and $\mathrm{Mcl}-1$ during tumor progression. ${ }^{9}$ Similarly, in a study of renal cancers, $40 \%$ of patient samples had observable Bcl-2 expression levels. ${ }^{11}$ In prostate cancer, prior studies have demonstrated that $\mathrm{Bcl}-2$ overexpression is associated with the progression of prostate cancer to an androgen-independent form. ${ }^{12}$ Further studies have shown that in the androgen-responsive prostate cancer line, LNCaP, overexpression of $\mathrm{Bcl}-2$ permits continued growth in vitro and tumor formation in vivo despite androgen deprivation. ${ }^{13} \mathrm{~A}$ subsequent IHC investigation of 64 
adenocarcinomas of the prostate found that 25,100 , and 81 percent of the tumor samples exhibited observable levels of $\mathrm{Bcl}-2, \mathrm{Bcl}-\mathrm{x}_{\mathrm{L}}$, and $\mathrm{Mcl}-1$, respectively. ${ }^{14}$ Studies of $\mathrm{Bcl}-2$ family protein levels in colon cancer samples identified opposite correlations between patient prognosis and $\mathrm{Bcl}-2$ or $\mathrm{Mcl}-1$ protein levels using $\mathrm{IHC} .^{15,16}$ Furthermore, IHC studies of ovarian cancer have recently suggested a more prominent role for $\mathrm{Mcl}-1$ compared with $\mathrm{Bcl}-2$ or $\mathrm{Bcl}-\mathrm{x}_{\mathrm{L}} .{ }^{17}$ As a group, these studies have provided a firm foundation for the development and use of antiapoptotic Bcl-2 subfamily inhibitors in cancer development, but due to their use of mainly patientderived samples, they have precluded the ability to perform additional studies into how to improve compound targeting and/ or to understand why there are highly variable clinical end points between the different studies, often within the same cancer type. ${ }^{18}$ None of these studies, however, have examined the relative abundance of all six antiapoptotic Bcl-2 subfamily members in a readily available set of cancer cell lines.

The progression into clinical trials of compounds with selective activity for $\mathrm{Bcl}-2$ and $\mathrm{Bcl}-\mathrm{x}_{\mathrm{L}}$ has made this issue especially urgent. For example, several pre-clinical studies have shown that tumors highly expressing $\mathrm{Mcl}-1$ are typically resistant to compounds that selectively target $\mathrm{Bcl}-2$ and $\mathrm{BCl}-\mathrm{X}_{\mathrm{L}} \cdot{ }^{19,20}$ Comprehensive studies into the levels of each of the antiapoptotic Bcl-2 subfamily members may therefore allow for better optimization of antiapoptotic Bcl-2 subfamily inhibitors.

\section{Results}

The expression levels of all six antiapoptotic Bcl-2 subfamily members (Bcl-2, Bcl- $\mathrm{x}_{\mathrm{L}}, \mathrm{Bcl}-\mathrm{B}, \mathrm{Bcl}-\mathrm{W}, \mathrm{Bfl}-1$, and $\left.\mathrm{Mcl}-1\right)$ were
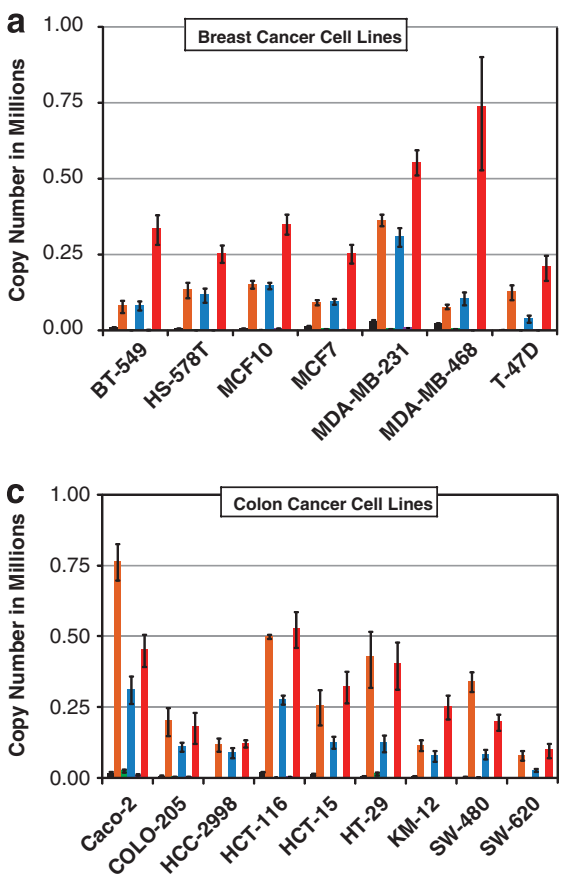

$\mathrm{Bcl}-2=\mathrm{Bcl}-\mathrm{xL}=\mathrm{Bcl}-\mathrm{B} \approx \mathrm{Bcl}-\mathrm{W}=\mathrm{Bfl} 1=\mathrm{Mcl} 1$
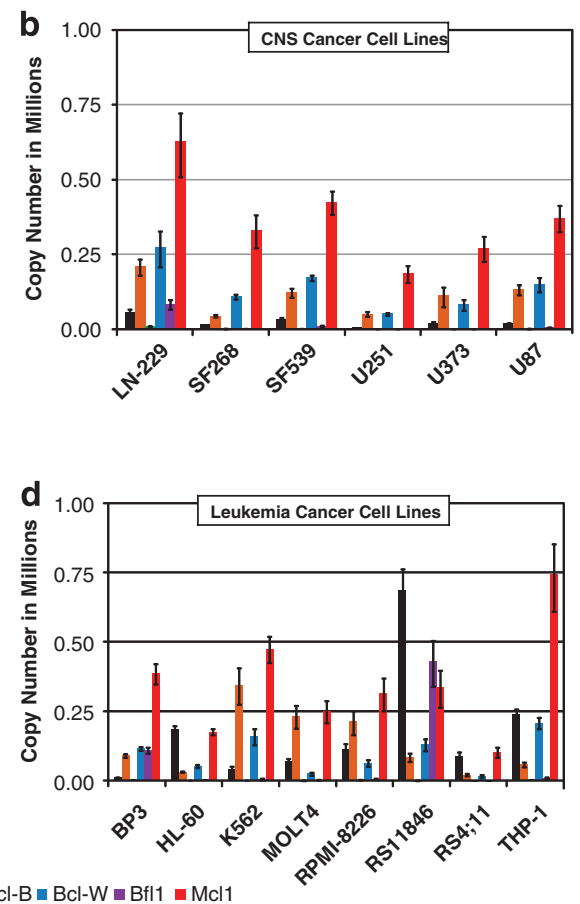

Figure 2 Expression of the six antiapoptotic Bcl-2 subfamily members in the breast, CNS, colon, and leukemia cancer cell lines. (a-d) Bar graphs representing the relative copy number of each Bcl-2 subfamily member: Bcl-2 in black, Bcl- $\mathrm{x}_{\mathrm{L}}$ in orange, Bcl-B in green, Bcl-W in blue, Bfl1 in purple, and Mcl1 in red. Cell lines are grouped according to their identified tissue type. Error bars represent S.E.M.

studied in 68 human cancer cell lines and in cultured human dermal fibroblast (HDF) cells using quantitative real-time polymerase chain reaction (qPCR) techniques. In addition, control total RNA samples from the brain, cervix, colon, kidney, lung, melanocyte, ovary, and prostate tissues were obtained and screened as outlined in the Materials and Methods section. The average, maximum, and minimum $C_{\mathrm{t}}$ values were determined and these were then transformed into initial copy number values, which are charted in Figures 2 and 3. Distributions of the expression levels of the six genes in all cell lines are presented in Figure 4. Prior immunohistochemical studies of $\mathrm{Bcl}-2$ and $\mathrm{Bcl}-\mathrm{x}_{\mathrm{L}}$ protein levels in breast cancer cell lines, ${ }^{21} \mathrm{Mcl}-1$ protein levels in melanoma cell lines ${ }^{22}$ and $\mathrm{Bfl}-1$ protein levels in leukemia and lymphoma cell lines ${ }^{23}$ correlate directly with levels observed for each of the respective cell lines studied in this survey.

Bcl-2 subfamily expression in breast, CNS, colon, lung, ovarian, prostate, and renal cancer lines. The majority of solid tumor-derived cell lines displayed similar relative antiapoptotic Bcl-2 subfamily expression patterns with $\mathrm{Mcl}-1$ having the highest level of mRNA expression of all Bcl-2 subfamily members (Figures 2 and 3). bcl- $x_{L}$ and $b c l-W$ mRNAs were also detected at intermediate levels in most cell lines with $\mathrm{Bcl}-\mathrm{x}_{\mathrm{L}}$ expression levels approaching those of $\mathrm{Mcl}-1$ in a subset of cell lines in each cancer type. Expression of Bcl-2, Bfl-1, and Bcl-B coding mRNA was observed primarily at low levels. A number of cell lines throughout these tissue types have increased mRNA expression of Bfl-1 when compared with the primary human dermal fibroblast (HDF) sample used as a comparator. These include the CNS cancer cell line LN-229 (15-fold), the non-small cell lung 

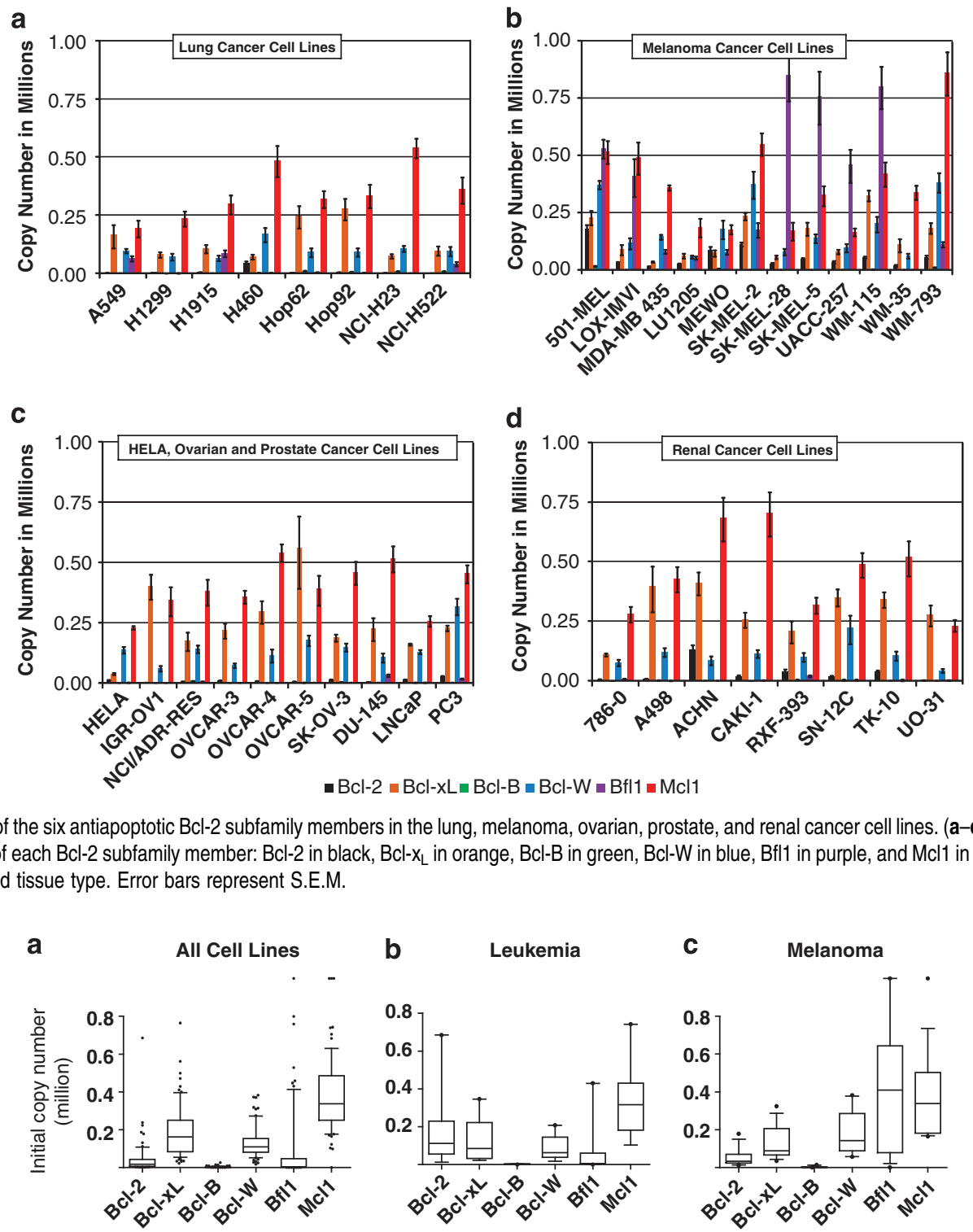

Figure 3 Expression of the six antiapoptotic Bcl-2 subfamily members in the lung, melanoma, ovarian, prostate, and renal cancer cell lines. (a-d) Bar graphs representing the relative copy number of each Bcl-2 subfamily member: Bcl-2 in black, Bcl- $\mathrm{L}_{\mathrm{L}}$ in orange, Bcl-B in green, Bcl-W in blue, Bfl1 in purple, and Mcl1 in red. Cell lines are grouped according to their identified tissue type. Error bars represent S.E.M.
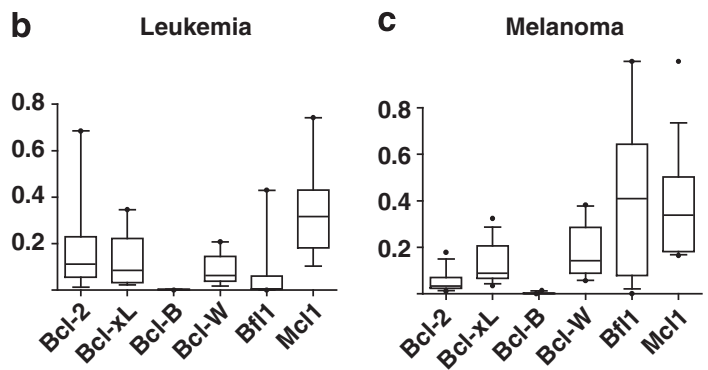

Figure 4 Range of antiapoptotic Bcl-2 subfamily expression. (a-c) Box and Whisker plot of the 10-90th percentile of the relative copy number distribution across all 68 cell lines studies (a), the 8 leukemia cell lines (b), or the 12 melanoma cell lines (c)

cancer lines A549, H1915 and $\mathrm{NCl}-\mathrm{H} 522$ (12, 16 and 8-fold, respectively), the prostate cancer cell lines PC-3 and DU-145 (three and five-fold), and the renal cancer cell line RXF-393 (four-fold). Furthermore, the CNS cancer cell line LN-229, the lung cancer cell line $\mathrm{H} 460$ and the renal cancer cell lines ACHN, RXF-393, and TK-10 have increased expression of $\mathrm{Bcl}-2$ when compared with the HDF sample. In addition, of all 69 lines screened, only Caco-2 had significant overexpression of $\mathrm{Bcl}-\mathrm{B}$ compared with HDF cells. Interestingly, the control samples show at least a two-fold increase in mRNA expression of $\mathrm{Bcl}-2$ in the kidney, lung, cervix, and ovary tissue and of $\mathrm{Bcl}-\mathrm{B}$ in the kidney, cervix, and colon tissue (Supplementary Figure 2).

Bcl-2 subfamily expression in leukemia/lymphoma cancer lines. The antiapoptotic $\mathrm{Bcl}-2$ subfamily expression has been highly studied in both leukemia/lymphoma cell lines and primary cell samples, yet nearly all studies have focused on the three proteins $\mathrm{Bcl}-2, \mathrm{Bcl}-\mathrm{x}_{\mathrm{L}}$, and $\mathrm{Mcl}-1{ }^{19}$ Elevated levels of $\mathrm{Bcl}-2$ have been correlated with shorter patient survival and this has lead to the development of a number of anti-Bcl-2 therapeutics. ${ }^{24}$ Meanwhile, increased Mcl-1 has been correlated with more advanced forms of chronic lymphocytic leukemia and resistance to both chemotherapy and $\mathrm{Bcl}-2$ inhibitors. ${ }^{19,20} \mathrm{Bfl}-1$ has also been reported to be overexpressed in B-cell lymphoma ${ }^{23}$ and is associated with increased resistance to apoptotic stimulation, ${ }^{25}$ and treatment with the $\mathrm{Bcl}-\mathrm{x}_{\mathrm{L}} / \mathrm{Bcl}-2$ antagonist $\mathrm{ABT}-737^{20,26}$

Our data demonstrate high levels of $\mathrm{Bcl}-2$ expression in seven of eight leukemia/lymphoma lines studied (Figure 2d). Only one cell line, BP3, shows low levels of Bcl-2 expression, while displaying increased $\mathrm{Bfl}-1$ expression, 20 -fold higher than in HDF cells. In addition to Bcl-2, RS11846 cells also show very high (80-fold) levels of Bfl-1 expression compared 
with HDF cells. All eight leukemia/lymphoma lines show moderate levels of $m c l-1, b c l-x_{L}$, and $b c l-W$ mRNA. Thus, leukemia and lymphoma cell lines, more than any other type of cancer cell line studied, are characterized by a wide diversity of antiapoptotic Bcl-2 subfamily expression (Figure 4b).

Bcl-2 subfamily expression in melanoma cancer lines. Bcl-2 subfamily expression studies of melanoma and melanocytes have identified that while levels of $\mathrm{Bcl}-2, \mathrm{Bcl}-\mathrm{x}_{\mathrm{L}}$, and $\mathrm{Mcl}-1$ levels do not vary greatly between the normal and the cancerous state, ${ }^{8} \mathrm{Bcl}-2$ subfamily proteins are highly expressed in melanoma and a high Bcl-2/Bax ratio has been found to correlate with increased CD95/Fas-mediated apoptosis. $^{27}$ Furthermore, $\mathrm{Mcl}-1$ and $\mathrm{Bcl}-\mathrm{x}_{\mathrm{L}}$ were found to be upregulated during melanoma progression and metastases, whereas Bcl-2 levels were downregulated. Finally, it was observed that survival of melanoma lines after proteosomal treatment relies on increased $\mathrm{Mcl}-1$ rather than $\mathrm{Bcl}-2$ protein expression, ${ }^{28}$ suggesting prominent roles for members of the $\mathrm{Bcl}-2$ subfamily other than $\mathrm{Bcl}-2$ in melanoma.

Our study of 12 melanoma cell lines found that all but one sample (WM-35) had significantly higher Bfl-1 expression than the HDF cells, as well as in all other cancer types investigated $(P<0.0001$; Figure $4 \mathrm{c}$, Supplementary Figure 1A). Furthermore, in four of the 12 lines (SK-MEL-28, SK-MEL-5, UACC-257, and WM-115), Bfl-1 was the highest expressed antiapoptotic Bcl-2 subfamily member. In comparison to HDF cells, the 11 melanoma lines have $\mathrm{Bfl}-1$ expression levels of 9-150-fold higher. Interestingly, Bcl-2 expression in all 12 lines also has the highest average expression for any cancer type other then leukemia $(P=0.0001$; Supplementary Figure 1B). Increased Bfl-1 expression was also observed in the total RNA from the melanocyte control sample with a 50-fold overexpression compared with the HDF comparator (Supplementary Figure 2). These data agree with the previous studies that found increased $\mathrm{Bcl}-2$ in melanoma as well as point to other $\mathrm{Bcl}-2$ subfamily members as contributors to apoptosis resistance. High levels of $\mathrm{Bcl}-\mathrm{x}_{\mathrm{L}}, \mathrm{Bcl}-\mathrm{W}$, and $\mathrm{Mcl}-1$ were also observed across all melanoma lines studied (Figure 4c).

Small molecule Bcl-2 inhibitors. To assess the ability of the $\mathrm{qPCR}$ data to predict sensitivity or resistance to $\mathrm{Bcl}-2$ family antagonists in cell culture, we selected a subset of the tumor cell lines to be challenged with small molecule inhibitors of antiapoptotic Bcl-2 family proteins. We tested $\mathrm{ABT}-737,{ }^{26}$ which is known to specifically target $\mathrm{Bcl}-2, \mathrm{Bcl}-\mathrm{x}_{\mathrm{L}}$, and $\mathrm{BCl}-\mathrm{W},{ }^{29}$ as well as two derivatives of the pan-active Bcl-2 subfamily inhibitor, Apogossypol, which were recently reported by our laboratories (Figure $5 \mathrm{a}$ ). ${ }^{30,31}$ The $\mathrm{IC}_{50}$ values for each of these three small molecules tested against the six antiapoptotic Bcl-2 subfamily members, as determined by their ability to displace a fluorochrome-conjugated $\mathrm{BH} 3$ Bid peptide, are presented in Table $1^{29,30}$ These data demonstrate that the two Apogossypol derivatives have broader cross-reactivity compared with ABT-737, as $8 \mathrm{~J}$ is able to bind to all of the subfamily members except for Bfl-1 at a uniform $\mathrm{IC}_{50}$ value of near $1 \mu \mathrm{M}$, whereas $8 \mathrm{Q}$ exhibits uniform $\mathrm{IC}_{50}$ values for all six members at approximately $1 \mu \mathrm{M}$. In contrast, although $\mathrm{ABT}-737$ is not active against
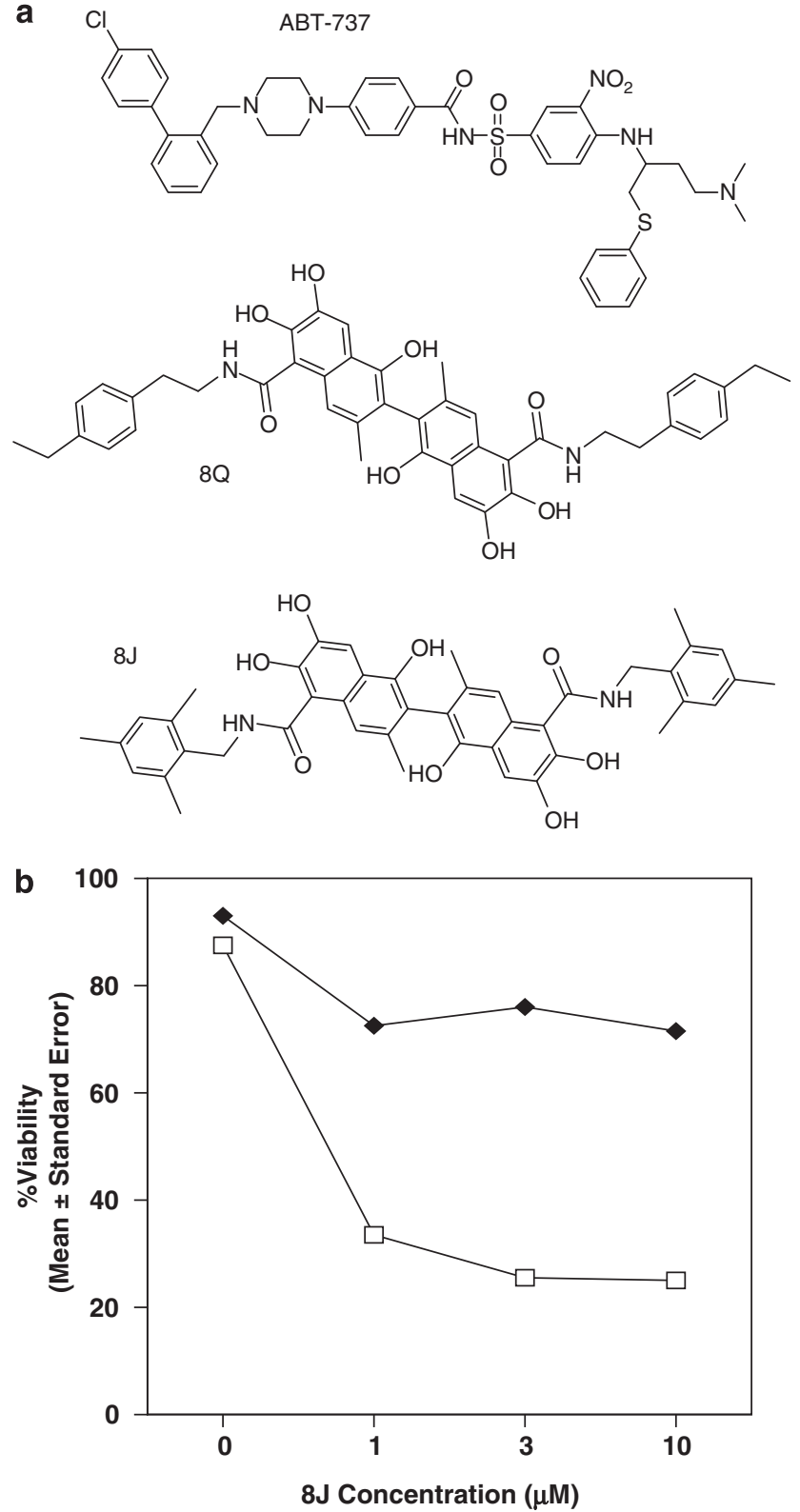

Figure 5 Chemical structures of $\mathrm{Bcl}-2$ antagonists. (a) Chemical structures of the three Bcl-2 inhibitors studied. (b) Cell viability of WT-MEF cells (white squares) or bax ${ }^{-1-} b^{-2} k^{-1}$ DKO MEF cells (solid squares) treated with compound $8 \mathrm{~J}$ at varying concentrations

Table 1 Fluorescence polarization displacement assay of the three Bcl-2 antagonists to each of the six antiapoptotic Bcl-2 subfamily members

\begin{tabular}{llllcccc}
\hline & Bcl- $\mathbf{x}_{\mathbf{L}}$ & $\mathbf{B c l - 2}$ & Bcl-W & Mcl-1 & Bcl-B & Bfl-1 \\
\cline { 2 - 7 } & \multicolumn{7}{c}{ IC $_{\mathbf{5 0}}$ values $(\boldsymbol{\mu} \mathbf{M})$} \\
\hline ABT-737 & 0.064 & 0.12 & 0.024 & $>20$ & $>10$ & $>20$ \\
8J & 1.7 & 0.70 & 6.1 & 1.1 & 5.0 & 13.1 \\
8Q & 0.93 & 0.67 & 6.7 & 0.59 & 3.0 & 1.3
\end{tabular}

$\mathrm{Bfl}-1, \mathrm{Mcl}-1$, and $\mathrm{Bcl}-\mathrm{B}$, it is significantly more potent against the other members as compared with the Apogossypol derivatives. Hence, these compounds provide research tools to assess whether it is preferable to have a potent 
and sub-class selective inhibitor versus pan-Bcl-2 antagonists with moderate affinities (Table 1).

To validate that the studied compounds act primarily through the intended mechanism in restoring Bax/Bakmediated apoptosis, we used wild-type mouse embryo fibroblasts (MEFs) versus $\mathrm{bax}^{-/-} / \mathrm{bak}^{-/-}$double knockout (DKO) genotypes (Figure 5b). Compounds that kill using the intended mechanism should not show cytotoxic activity on Bax/Bak DKO cells. We observed that $8 \mathrm{~J}$ induces Bax/Bakdependent cell death with limited off-target cytotoxicity at concentrations up to $10 \mu \mathrm{M}$. This agrees with similar findings for $A B T-737$ and $8 Q$ reported previously. ${ }^{30,32}$

To determine the ability of each of the compounds to induce cell death in 36 selected tumor cell lines (listed in Figure 6a), we measured cell viability using the ATP-Lite assay (PerkinElmer, Waltham, MA, USA), which assesses levels of cellular ATP as a surrogate for cell viability. Each cell line was cultured with a range of compound concentrations in triplicate and the resulting $L D_{50}$ values were reported (Figure $6 \mathrm{a}$ ). In six of the studied cell lines, ABT-737 showed no effect across the compound concentration range tested. ABT-737 showed potent cytotoxic activity against leukemia/lymphoma lines, consistent with the observation that they exhibited significant $\mathrm{Bcl}-2$ expression. Similarly, in those lines with minimal Bcl-2 expression, ABT-737 was found to be the least active of the three compounds. A positive correlation between log $\mathrm{LD}_{50}$, [ABT-737] and bcl-2 mRNA copy number was observed with a correlation coefficient of $r=-0.7233$ ( $P$-value $>0.0001$; Figure $6 \mathrm{~b})$. Interestingly, no similar correlation between log $\mathrm{LD}_{50}$, [ABT-737] and $b c l-x_{L}$ or $b c l-W$ mRNA copy number was observed. Furthermore, as expected from prior literature that shows that suppression of $\mathrm{Mcl}-1$ via siRNA resulted in increased $A B T-737$ effectiveness, ${ }^{33}$ we observed that if we normalized the bcl-2 mRNA level to a uniform mcl-1 mRNA level across the panel of tumor cell lines, then the correlation improved to $r=-0.8081$ ( $P$-value $>0.0001)$. Similar normalization of the $b c l-2$ mRNA level to $b c l-x_{L}$ mRNA levels or to the sum of all other Bcl-2 subfamily mRNA levels resulted in $r$ values of -0.7735 or -0.8135 , respectively.

The compounds $8 \mathrm{Q}$ and $8 \mathrm{~J}$ had significantly smaller variations in their $L D_{50}$ ranges across the 36 screened tumor cell lines (Figure 7) presumably due to their cross-reactivity with most antiapoptotic Bcl-2 subfamily members. The poor affinity of $8 \mathrm{~J}$ for $\mathrm{Bfl}-1$ did not seem to impact its affect on
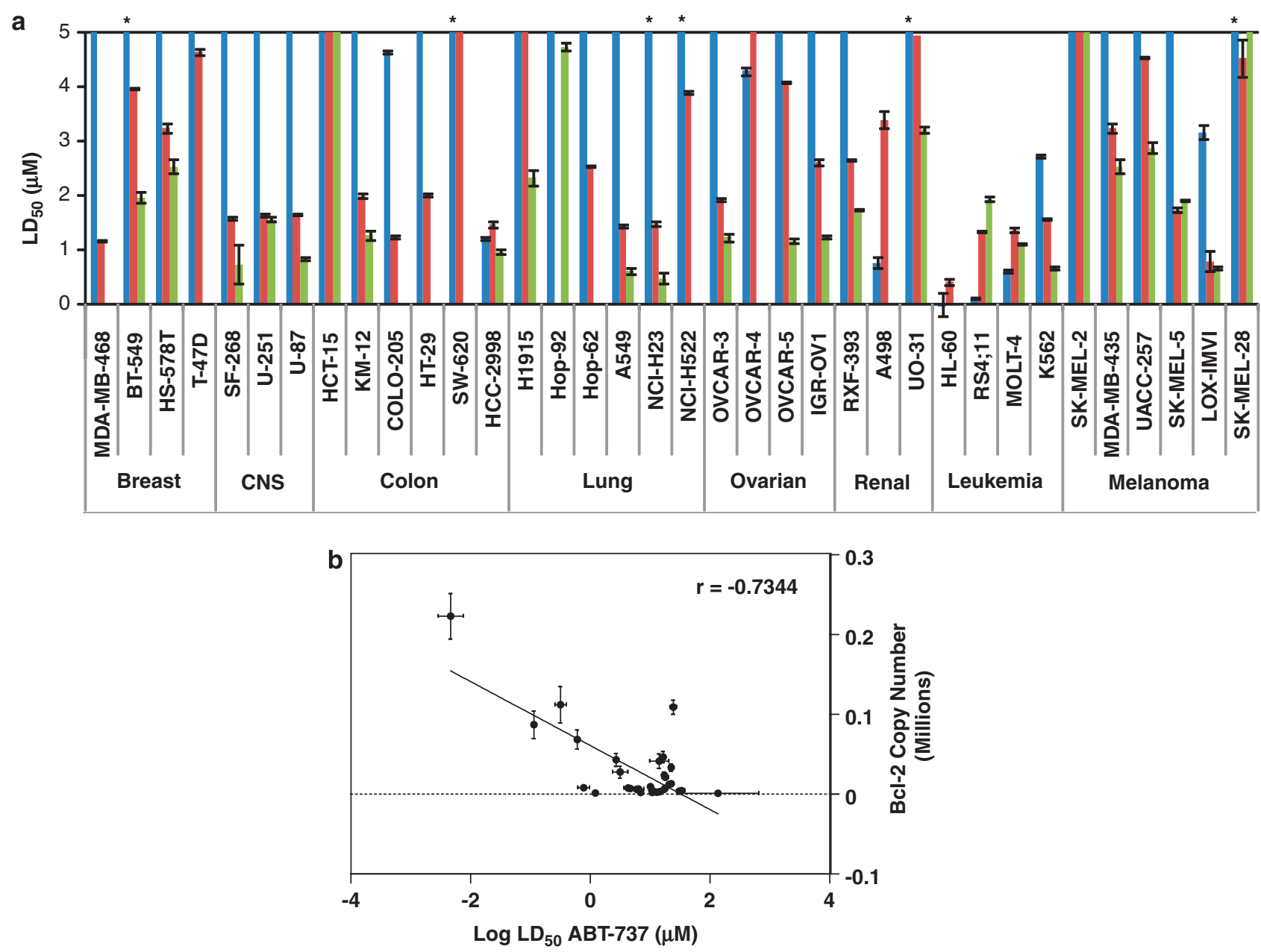

Figure 6 Ability of cells to evade apoptosis in presence of Bcl-2 inhibitors. (a) $\mathrm{LD}_{50}$ values for each of the three compounds $A B T-737$ (blue bars), $8 \mathrm{~J}$ (red bars), and $8 \mathrm{Q}$ (green bars) in 36 selected cell lines grouped according to their cancer type are shown. Error bars represent S.E.M. and the asterisks represent cell lines in which ABT-737 showed no apparent cell killing effect at a concentration of $30 \mu \mathrm{M}$. (b) Scatter plot of $B c-2$ mRNA copy number and the measured $\mathrm{LD}_{50}$ values for the 36 cell selected cell lines 


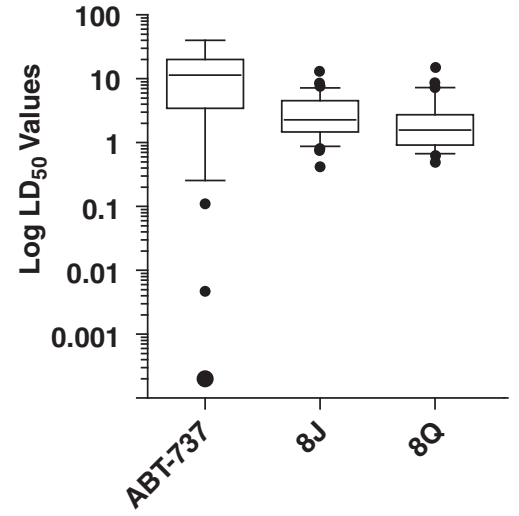

Figure 7 Range of compound $L_{50}$ values across the 36 cell lines studied. Box and Whisker plot of the 10-90th percentile of the measured $L_{50}$ values for the three compounds are represented on a log scale

melanoma cell lines, which were observed to have high bfl-1 mRNA levels in addition to high mcl-1 mRNA levels. This may be due to the difference in $\mathrm{LD}_{50}$ values between $\mathrm{Bfl}-1$ and the other family members being only one order of magnitude, whereas ABT-737 shows more than three orders of magnitude selection for Bcl-2 (Table 1) over Bfl-1. Notably, the colon cancer line HCT-115 presented $\mathrm{LD}_{50}$ values of $>15 \mu \mathrm{M}$ for all three compounds tested and may therefore prove to be an interesting model for future studies of cancer cells demonstrating non-Bcl-2 subfamily-mediated resistance to apoptosis.

\section{Discussion}

In this study, we investigated the expression levels of all six antiapoptotic Bcl-2 subfamily members at the mRNA level in 68 cancer cell lines across nine basic tissue types using qPCR techniques. We then measured the ability of chemical $\mathrm{Bcl}-2$ inhibitors to induce cell death in 36 of the studied lines. In seven of nine tissue types, Mcl-1 was expressed at the highest levels among the family members, comprising from 40-60\% of $\mathrm{Bcl}-2$ subfamily mRNA present. $\mathrm{Bcl}-2$ was found to be prominently expressed in leukemia/lymphoma lines but not in solid tumor cell lines. Melanoma cell lines and the melanocyte control sample all significantly overexpressed Bfl-1 at levels 9-150-fold higher than in HDF reference cells. We then studied the ability of three previously described $\mathrm{Bcl}-2$ subfamily inhibitors ${ }^{26,30}$ to induce cell death in a collection of the 36 cell lines screened for mRNA copy number.

Although we acknowledge that mRNA levels cannot definitely predict protein levels present in a cell, prior studies of the antiapoptotic $\mathrm{Bcl}-2$ subfamily members protein levels correlate well with our findings. ${ }^{21-23}$ It has also been shown that constant turnover of both protein and mRNA levels are integral parts of $\mathrm{Bcl}-2$ regulation. ${ }^{34}$ Moreover, to investigate the ability of the qPCR data to predict the efficacy of $\mathrm{Bcl}-2$ antagonists, we tested three chemical Bcl-2 inhibitors (ABT-737, 8Q, and 8J) against a selection of the tumor cell lines studied. In support of the predictive nature of the mRNA studies here presented, we found an inverse correlation $(r=-0.7344, P<0.0001)$ between ABT-737-induced LD $_{50}$ values and $b c l-2$ mRNA copy number (Figure 6b). Furthermore, this correlation was modulated by Mcl-1 $(r=-0.8081)$ and total antiapoptotic Bcl-2 subfamily $(r=-0.8135)$ mRNA levels, consistent with prior preclinical studies using $\mathrm{Mcl}-1$ knockdown approaches. ${ }^{20}$ Interestingly, $L D_{50}$ values for ABT-737 did not correlate with either $b c l-x_{L}$ or $b c /-W$ mRNA expression despite biochemical analysis showing that ABT-737 has potent nanomolar affinity to these proteins. This result suggests that either $\mathrm{ABT}-737$ binding to $\mathrm{Bcl}-\mathrm{x}_{\mathrm{L}}$ or $\mathrm{Bcl}-\mathrm{W}$ does not result in inhibition of their antiapoptotic functionality, or these two proteins are not critical for the survival of the tumor cell lines studied in routine cultures. However, it must be noted that therapies targeting antiapoptotic Bcl-2 family proteins may sensitize tumor cells to apoptotic stimuli, such as chemotherapy or radiation, without displaying single-agent cytotoxic activity.

A similar, though much weaker correlation was identified between observed $\mathrm{LD}_{50}$ values for compound $8 \mathrm{~J}$ and calculated bcl-2 mRNA copy number $(r=-0.4143$, $P=0.01$ ). Given the wider activity across all subfamily members and the small range of observed $L D_{50}$, improved information on the individual importance of each Bcl-2 subfamily member responsible for such a pan-active inhibitor would require either the discovery of a highly responsive cell line, development of improved Apogossypol derivatives with sub-micromolar affinities for individual Bcl-2 subfamily members, or intense studies of single cell lines while knocking out different subfamily members using siRNA techniques. Such multivariate analysis could prove very informative in the further optimization of pan-active Bcl-2 subfamily inhibitors. In contrast, a more broad-spectrum Apogossypol derivative, $8 \mathrm{Q}$, which shows micromolar affinity against all six Bcl-2 subfamily members did not have an observable correlation between its $L D_{50}$ values and the mRNA levels of any single subfamily member. This is likely due to the small range of $L D_{50}$ values observed in the tested cell lines. Nevertheless, the correlations identified, especially for ABT-737, demonstrate the predictive nature of the reported qPCR studies.

Our data support and supplement to some extent results reported in prior studies focused on single cancer tissue types that looked at only a subset of the subfamily members (e.g. $\mathrm{Bcl}-2, \mathrm{Bcl}-\mathrm{x}_{\mathrm{L}}$, or $\mathrm{Mcl}-1$ ) assessing relative protein levels using IHC methods. These studies found that for all cancer types, except leukemia, Mcl-1 is upregulated and can often be associated with some metric of cancer progression or poor patient prognosis. ${ }^{10,15,17}$ Our data agree with these studies in as much as $\mathrm{mcl}-1 \mathrm{mRNA}$ is prominently expressed in most tumor cell lines. In this regard, it is typical that only the most aggressive cancers can be established readily as cell lines that can be easily passaged long-term in culture. Thus, the striking expression of $\mathrm{mcl}-1$ mRNA observed in established tumor cell lines may be a reflection of their more aggressive character. In addition, siRNA studies targeting $\mathrm{Mcl}-1$ have demonstrated that reduction of $\mathrm{mcl}-1 \mathrm{mRNA}$ levels causes increased sensitivity to $A B T-737^{35}$ and decreased resistance to anoikis. ${ }^{22}$

We must note that qPCR techniques are not able to differentiate among the posttranslational modifications of individual members of the $\mathrm{Bcl}-2$ subfamily at the protein level. In this regard, it has been reported that significant stabilization 
or proteolysis of $\mathrm{Bcl}-2$ and $\mathrm{Mcl}-1$ protein may be facilitated by phosphorylation. ${ }^{36}$ Furthermore, the turnover of antiapoptotic $\mathrm{Bcl}-2$ subfamily members has been reported to be dependent on several other proteins, including the levels of proapoptotic Bcl-2 subfamily members, the E3 ubiquitin ligase, MULE/ LASU1, or individual caspases, to name a few. ${ }^{37}$ Although this is the case, we feel that by presenting a wide survey of the antiapoptotic $\mathrm{Bcl}-2$ subfamily expression in cancer types this study will allow more dedicated investigation into these various control systems. A prior focused study of apoptosis gene expression in the $\mathrm{NCl}-60$ cells lines only characterized the expression of $\mathrm{Bcl}-2$ and $\mathrm{Bcl}-\mathrm{X}_{\mathrm{L}}$ using $\mathrm{qPCR} .{ }^{38}$ It should also be noted that many of the prior studies were conducted with primary patient samples that are not readily available throughout the scientific community, nor in sufficient quantity to allow repeated probing for the discernment of $L D_{50}$ values in the context of drug optimization programs. Thus, further development of the $\mathrm{Bcl}-2$ field requires the analysis of available tumor cell lines, which serve as models to refine knowledge of biochemical signaling pathways and develop improved antiapoptotic Bcl-2 subfamily-targeted inhibitors. Owing to the large number of studies already conducted on the $\mathrm{NCl}-60$ panel of cancer lines, we attempted to include as many of these cell lines as possible in our analysis.

As a result of this study, we feel that the current difficulties of $\mathrm{Bcl}$-2-targeted inhibitors in the clinic ${ }^{39}$ may be understood through our observations that the severe upregulation of $\mathrm{Bcl}-2 / \mathrm{Bcl}-\mathrm{x}_{\mathrm{L}}$ seems to be isolated to leukemia like cell lines and that in other cancer types a strategy targeted to $\mathrm{Mcl}-1$ inhibition (or $\mathrm{Mcl}-1 / \mathrm{Bfl}-1$ inhibition in the case of melanoma) may prove to be more successful. In addition, although targeting individual members of the antiapoptotic Bcl-2 subfamily may initially prove promising, recent studies with ABT-737 suggest that resistance to the compound is a consequence of the ability of cancer cells to adapt and express other Bcl-2 subfamily members. ${ }^{20}$ Thus, the development of pan-active $\mathrm{Bcl}-2$ inhibitors may lead to more successful therapeutic outcomes to be achieved. Our data illustrates that even within a cancer tissue type significant deviations may be seen between cell lines. Taken together, these data argue clinical trials seeking to develop Bcl-2 inhibitors should minimally include assessment of the expression of all six antiapoptotic Bcl-2 subfamily members so that the activity profile of compounds can be connected with the repertoire of $\mathrm{Bcl}-2$ family members present within the tumor of individual patients.

\section{Materials and Methods \\ Cell lines and total RNA samples. Cell lines used in this study were assembled through the generosity of research groups at The Burnham Institute for Medical Research. The cell lines SK-MEL-2, SK-MEL-28, and HS-578T were acquired from the ATCC. Primary human dermal fibroblast (HDF) cells were purchased from Cascade Biologics (Invitrogen, Carlsbad, CA, USA). The FirstChoice Human Total RNA survey panel purchased from Applied Biosystems (Foster City, CA, USA).}

Cell culture. Cell lines included in the NCI-ADS cancer cell panel were grown in RPMl 1640 medium containing $5 \mathrm{mM}$ Glutamax (Invitrogen) supplemented with $10 \%$ fetal bovine serum (Invitrogen) and 1\% antibiotic/antimycotic (Invitrogen). All other immortalized cell lines were grown in their recommended medium containing $5 \mathrm{mM}$ Glutamax (Invitrogen) supplemented with 10\% fetal bovine serum (Invitrogen) and $1 \%$ antibiotic/antimycotic (Invitrogen). All cultures were grown at $37^{\circ} \mathrm{C}$ in a humidified incubator with $5 \% \mathrm{CO}_{2}$. Cells were maintained at $40-80 \%$ confluence for a minimum of 1 week before RNA extraction. The HDF cells were cultured as recommended and total RNA was harvested after 6 and 10 phase doublings.

Quantitative PCR. Total RNA from $3 \times 10^{6}$ cells from each line were collected at $70-80 \%$ confluence and prepared using the Illustra RNAspin mini total RNA extraction kit (GE Healthcare, Piscataway, NJ, USA) according to the manufacturer's recommendations for cultured cells. Each RNA sample was quantified with a NanoDrop ND-1000 Spectrophotometer and the RNA integrity of each sample was further confirmed using a BioRad Experion Bioanalyzer (BioRad, Hercules, CA, USA) to assess the ratio of 28 and $18 \mathrm{~s}$ RNAs. All samples exhibited 28/18 S RNA ratios of 1.8-2.2, which indicates the presence of high-quality total RNA. The complementary DNA was produced using qScript cDNA Supermix (Quanta Biosciences, Gaithersburg, MD, USA) according to manufacturer's recommendations in $20 \mu \mathrm{l}$ reaction mixtures using $400 \mathrm{ng}$ of total RNA as the template. The resultant CDNA was diluted $1: 7$ being used in $\mathrm{PPCR}$.

Primers for use in qPCR were identified from a search of the Quantitative PCR Primer Database when available or designed using freely available software from IDT or Invitrogen. Identified primers were purchased from Invitrogen and tested for the amplification of a single uniform amplicon through analysis of SYBR melting curves for three of the target cell lines: $\mathrm{H} 460, \mathrm{~A} 549$ and H1299. Standard curves used to transform $C_{\mathrm{t}}$ values to allow absolute quantification of the initial cDNA copy number for each of the genes studied were collected and showed linear amplification over six orders of magnitude, covering the $C_{t}$ ranges of all included samples $(r>0.994)$. In addition, negative controls for each primer pair were run in the absence of cDNA template to assure that all readings were the result of the intended amplification reaction. The primers are listed in supplementary Table 1. To avoid amplification of genomic DNA, each primer pair straddled at least one intron/ exon border.

All qPCR reactions were performed in $17 \mu \mathrm{l}$ reaction mixtures containing $2 \mu \mathrm{l}$ of the diluted cDNA, $8.5 \mu$ l PerfeCta SYBR green FastMix, Low ROX (Quanta Biosciences), $1 \mu \mathrm{l}$ each of $7.5 \mu \mathrm{M}$ forward and reverse primers, and $4.5 \mu \mathrm{l}$ molecular grade water. Each sample was run in duplicate on a 96-well plate with the Mx3000P qPCR system (Stratagene, La Jolla, CA, USA). Each plate probed the expression of five variable target cell lines and a constant CDNA preparation of human dermal fibroblast cells (Invitrogen) for the six members of the Bcl-2 subfamily. Each group of five target cell lines was run in triplicate against three different reporter genes: GAPDH, RPII and $\beta_{2}$-microglobulin. Thermocycling conditions consisted of an initial polymerase inactivation step at $95^{\circ} \mathrm{C}$ for $10 \mathrm{~min}$, followed by 40 cycles at $95^{\circ} \mathrm{C}$ for $30 \mathrm{~s}, 55^{\circ} \mathrm{C}$ for $1 \mathrm{~min}$, and $72^{\circ} \mathrm{C}$ for $1 \mathrm{~min}$. Afterwards, melting curves were generated to confirm a single uniform peak. Baselines were automatically set by the software and the threshold was manually set to a single value of 500 for all experiments. A method of analyzing each resulting amplification plot and melting curve, outlined by Nolan et $a l^{40}$, was used to identify any abnormal data that were subsequently excluded from further analysis.

Calculated $C_{t}$ values were exported to Microsoft Excel and Graphpad Prism for further analysis. To control for plate-to-plate variation, data on each plate were normalized to the $C_{\mathrm{t}}$ values determined for the Mcl-1 standard curve. Each cell type's data was further normalized to the average level of mRNA expression $\left(C_{\mathrm{t}}\right.$ value) of RPII across all cell lines. The S.E.M. values for the six replicates for each gene in all 68 cell lines were then calculated from these normalized $C_{t}$ values before transformation of the data into initial copy number values. The average \pm S.E.M. values were calculated and transformed into initial copy number values for the purpose of displaying the error bars in graphical representations of the data.

ATPLite analysis. The activity of three compounds against a selection of the human cancer cell lines was determined using the ATP-Lite 1-Step assay (PerkinElmer). All cells were seeded in RPMI 1640 medium with $5 \mathrm{mM}$ Glutamax (Invitrogen) supplemented with $5 \%$ fetal bovine serum (Invitrogen) and $1 \times$ antimitotic/antimycotic (Invitrogen). Cells were plated into 96-well plates (Greiner, Bio-One, Monroe, NC, USA) at varying initial densities in $100 \mu$ volumes such that they would reach $80-90 \%$ confluence 4 days after seeding. At $24 \mathrm{~h}$ after seeding, the medium of adherent lines was removed and fresh RPMI-1640 medium, supplemented as above, was added. Compounds were diluted to final concentrations of $30,10,4,1,0.3$, and $0.1 \mu \mathrm{M}$ with $0.1 \%$ DMSO and added to the samples in triplicate. Each sample plate was incubated at $37^{\circ} \mathrm{C}$ in a $5 \% \mathrm{CO}_{2}$ environment for $72 \mathrm{~h}$. Cell viability was evaluated using ATP-LITE reagent 
(PerkinElmer) and measurements were obtained on a Victor 2030 Explore (PerkinElmer). Data were normalized to DMSO control-treated cells and $\mathrm{LD}_{50}$ values were calculated in Graphpad Prism 5.2 (Graphpad Software).

Flourescence polarization assays (FPA) and cell viability assays. The FPA studies on $8 \mathrm{Q}$ and $8 \mathrm{~J}$ against $\mathrm{Bcl}-\mathrm{W}$ and $\mathrm{Bcl}-\mathrm{B}$ were conducted as previously described. ${ }^{29}$

The apoptotic activity of $8 \mathrm{~J}$ against mouse embryonic fibroblast (MEF) WT cells and MEF BAX/Bak double-knockout cells (DKO) was assessed by staining with Annexin $\mathrm{V}$ and $\mathrm{PI}$ as previously described..$^{30}$

\section{Conflict of interest}

The authors declare no conflict of interest.

Acknowledgements. We thank Coronado Biosciences (CSRA \#08-02) and the National Institutes of Health, National Cancer Institute (grants CA113318 and CA149668) for generous financial support. also thank Dr. Jeffrey Smith (Burnham Institute) for the kind gift of the MCF-7, MCF-10, and WM-35 cell lines, Dr. William Stallcup (Burnham Institute) for the kind gift of the U251 and U373 cell lines, Dr. Guy Salvesen (Burnham Institute) for the kind gift of the HL-60 cell line, Dr. Kristina Vuori (Burnham Institute) for the kind gift of the SK-OV-3, DU-145, LNCaP, LN-229 and U87 cell lines, and Dr. Ze'ev Ronai (Burnham Institute) for the kind gift of the 501-MEL, LU1205, MEWO, WM-115 and WM-793 cell lines and the melanocyte total RNA sample.

1. Reed JC. Dysregulation of apoptosis in cancer. J Clin Oncol 1999; 17: 2941-2953.

2. Adams JM, Cory S. The Bcl-2 protein family: arbiters of cell survival. Science 1998; 281 1322-1326.

3. Liang H, Fesik SW. Three-dimensional structures of proteins involved in programmed cell death. J Mol Biol 1997: 274: 291-302.

4. Green DR, Kroemer G. The pathophysiology of mitochondrial cell death. Science 2004; 305: 626-629.

5. Fesik SW. Promoting apoptosis as a strategy for cancer drug discovery. Nat Rev Cancer 2005; 5: 876-885.

6. Petros AM, Medek A, Nettesheim DG, Kim DH, Yoon HS, Swift K et al. Solution structure of the antiapoptotic protein bcl-2. Proc Natl Acad Sci USA 2001; 98: 3012-3017.

7. Rochaix P, Krajewski S, Reed JC, Bonnet F, Voigt JJ, Brousset P. In vivo patterns of Bcl-2 family protein expression in breast carcinomas in relation to apoptosis. J Pathol 1999; 187: $410-415$

8. Selzer E, Schlagbauer-Wadl H, Okamoto I, Pehamberger H, Pötter R, Jansen B. Expression of $\mathrm{Bcl}-2$ family members in human melanocytes, in melanoma metastases and in melanoma cell lines. Melanoma Res 1998; 8: 197-203.

9. Strik H, Deininger M, Streffer J, Grote E, Wickboldt J, Dichgans J et al. BCL-2 family protein expression in initial and recurrent glioblastomas: modulation by radiochemotherapy. J Neurol Neurosurg Psychiatry 1999; 67: 763-768.

10. Ding Q, He X, Xia W, Hsu JM, Chen CT, Li LY et al. Myeloid cell leukemia-1 inversely correlates with glycogen synthase kinase-3beta activity and associates with poor prognosis in human breast cancer. Cancer Res 2007; 67: 4564-4571.

11. Maruyama R, Yamana K, Itoi T, Hara N, Bilim V, Nishiyama T et al. Absence of Bcl-2 and Fas/CD95/APO-1 predicts the response to immunotherapy in metastatic renal cell carcinoma. Br J Cancer 2006; 95: 1244-1249.

12. McDonnell TJ, Troncoso P, Brisbay SM, Logothetis C, Chung LW, Hsieh JT et al. Expression of the protooncogene bcl-2 in the prostate and its association with emergence of androgen-independent prostate cancer. Cancer Res 1992; 52: 6940-6944.

13. Berchem GJ, Bosseler M, Sugars LY, Voeller HJ, Zeitlin S, Gelmann EP. Androgens induce resistance to bcl-2-mediated apoptosis in LNCaP prostate cancer cells. Cancer Res 1995; 55: 735-738.

14. Krajewska M, Krajewski S, Epstein Jl, Shabaik A, Sauvageot J, Song $K$ et al. Immunohistochemical analysis of bcl-2, bax, bcl-X, and mcl-1 expression in prostate cancers. Am J Pathol 1996; 148: 1567-1576.

15. Backus HH, van Riel JM, van Groeningen CJ, Vos W, Dukers DF, Bloemena E et al. Rb, mcl-1 and p53 expression correlate with clinical outcome in patients with liver metastases from colorectal cancer. Ann Oncol 2001; 12: 779-785.

16. Kouraklis G, Kakisis J, Theoharis S, Tzonou A, Glinavou A, Raftopoulos J et al. Prognostic significance and correlation with survival of bcl-2 and TGF-beta Rll in colon cancer. Dig Dis Sci 2003; 48: 2284-2289.

17. Shigemasa K, Katoh O, Shiroyama Y, Mihara S, Mukai K, Nagai N et al. Increased MCL-1 expression is associated with poor prognosis in ovarian carcinomas. Jpn J Cancer Res 2002; 93: 542-550.

18. Martin B, Paesmans M, Berghmans T, Branle F, Ghisdal L, Mascaux C et al. Role of Bcl-2 as a prognostic factor for survival in lung cancer: a systematic review of the literature with meta-analysis. Br J Cancer 2003; 89: 55-64.

19. Kitada S, Reed JC. MCL-1 promoter insertions dial-up aggressiveness of chronic leukemia. J Natl Cancer Inst 2004; 96: 642-643.

20. Vogler M, Butterworth M, Maijd A, Walewska RJ, Sun XM, Dyer MJ et al. Concurrent upregulation of $\mathrm{BCL}-\mathrm{XL}$ and $\mathrm{BCL2A1}$ induces approximately 1000-fold resistance to ABT-737 in chronic lymphocytic leukemia. Blood 2009; 113: 4403-4413.

21. Zapata JM, Krajewska M, Krajewski S, Huang RP, Takayama S, Wang HG et al. Expression of multiple apoptosis-regulatory genes in human breast cancer cell lines and primary tumors. Breast Cancer Res Treat 1998; 47: 129-140.

22. Boisvert-Adamo $\mathrm{K}$, Longmate $\mathrm{W}$, Abel EV, Aplin AE. Mcl-1 is required for melanoma cell resistance to anoikis. Mol Cancer Res 2009; 7: 549-556.

23. Brien G, Trescol-Biemont MC, Bonnefoy-Berard N. Downregulation of Bfl-1 protein expression sensitizes malignant B cells to apoptosis. Oncogene 2007; 26: 5828-5832.

24. Tse C, Shoemaker AR, Adickes J, Anderson MG, Chen J, Jin S et al. ABT-263: a potent and orally bioavailable Bcl-2 family inhibitor. Cancer Res 2008; 68: 3421-3428.

25. Wang CY, Guttridge DC, Mayo MW, Baldwin Jr AS. NF-kappaB induces expression of the Bcl-2 homologue A1/Bfl-1 to preferentially suppress chemotherapy-induced apoptosis. Mol Cell Biol 1999; 19: 5923-5929.

26. Oltersdorf T, Elmore SW, Shoemaker AR, Armstrong RC, Augeri DJ, Belli BA et al. An inhibitor of Bcl-2 family proteins induces regression of solid tumours. Nature 2005; 435: $677-681$

27. Raisova M, Hossini AM, Eberle J, Riebeling C, Wieder T, Sturm I et al. The Bax/Bcl-2 ratio determines the susceptibility of human melanoma cells to CD95/Fas-mediated apoptosis. J Invest Dermatol 2001; 117: 333-340.

28. Wolter KG, Verhaegen M, Fernández Y, Nikolovska-Coleska Z, Riblett M, de la Vega CM et al. Therapeutic window for melanoma treatment provided by selective effects of the proteasome on Bcl-2 proteins. Cell Death Differ 2007; 14: 1605-1616.

29. Zhai D, Jin C, Satterthwait AC, Reed JC. Comparison of chemical inhibitors of antiapoptotic Bcl-2-family proteins. Cell Death Differ 2006; 13: 1419-1421

30. Wei J, Kitada S, Rega MF, Emdadi A, Yuan H, Celliti J et al. Apogossypol derivatives as antagonists of antiapoptotic Bcl-2 family proteins. Mol Cancer Ther 2009; 8: 904-913.

31. Wei J, Kitada S, Rega MF, Stebbins JL, Zhai D, Cellitti J et al. Apogossypol derivatives as pan-active inhibitors of antiapoptotic B-cell lymphoma/leukemia-2 (Bcl-2) family proteins. J Med Chem 2009; 52: 4511-4523.

32. Vogler M, Weber K, Dinsdale D, Schmitz I, Schulze-Osthoff K, Dyer MJ et al. Different forms of cell death induced by putative BCL2 inhibitors. Cell Death Differ 2009; 16: $1030-1039$

33. Chen S, Dai Y, Harada H, Dent P, Grant S. Mcl-1 down-regulation potentiates ABT-737 lethality by cooperatively inducing Bak activation and Bax translocation. Cancer Res 2007; 67: 782-791.

34. Akgul C. Mcl-1 is a potential therapeutic target in multiple types of cancer. Cell Mol Life Sci 2009; 66: 1326-1336.

35. Konopleva M, Contractor R, Tsao T, Samudio I, Ruvolo PP, Kitada S et al. Mechanisms of apoptosis sensitivity and resistance to the BH3 mimetic ABT-737 in acute myeloid leukemia. Cancer Cell 2006; 10: 375-388.

36. Ruvolo PP, Deng X, May WS. Phosphorylation of $\mathrm{Bc} 22$ and regulation of apoptosis. Leukemia 2001; 15: 515-522.

37. Czabotar PE, Lee EF, van Delft MF, Day CL, Smith BJ, Huang DC et al. Structural insights into the degradation of Mcl-1 induced by BH3 domains. Proc Natl Acad Sci USA 2007; 104: 6217-6222.

38. Amundson SA, Myers TG, Scudiero D, Kitada S, Reed JC, Fornace Jr AJ. An informatics approach identifying markers of chemosensitivity in human cancer cell lines. Cancer Res 2000; 60: 6101-6110.

39. O'Brien S, Moore JO, Boyd TE, Larratt LM, Skotnicki A, Koziner B et al. Randomized phase III trial of fludarabine plus cyclophosphamide with or without oblimersen sodium (Bcl-2 antisense) in patients with relapsed or refractory chronic lymphocytic leukemia. $J$ Clin Oncol 2007; 25: 1114-1120.

40. Nolan T, Hands RE, Bustin SA. Quantification of mRNA using real-time RT-PCR. Nat Protoc 2006; 1: 1559-1582

(c)

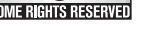
licensed under a Creative Commons Attribution-Noncommercial-No Derivative Works 3.0 License. To view a copy of this license, visit http:// creativecommons.org/licenses/by-nc-nd/3.0/

\section{Supplementary Information accompanies the paper on Cell Death and Disease website (http://www.nature.com/cddis)}

